\title{
AN OVERVIEW ON ASSESSMENT TESTS FOR ALZHEIMER'S DISEASE IN MEXICO. THE NATIONAL DEMENTIA SURVEY: A STUDY FROM THE MEXICAN GROUP OF SPECIALISTS IN DEMENTIAS
}

\author{
S.P. Ramírez Díaz', G. Albert Meza², R.E. Albrecht Junghanns, I.C. Zúñiga Gil ${ }^{4}$, M.A. Bedia Reyes ${ }^{5}$, \\ L.A. Barba Valadez ${ }^{6}$, E. Almanza Huante and Mexican Group of Specialists in Dementias $^{7}$
}

\begin{abstract}
Objective: To know the current status of the clinical assessment tests used to evaluate Alzheimer's disease (AD) and memory-related dementias in specific regions throughout Mexico. Design, patients and settings: Patients with objective memory impairment were subjected to a clinical survey in medical centers specializing in memory loss. Each patient's consultation was conducted like a routine clinical practice. Patient's data were recorded using an anonymous patient survey. The most prominent behavioral problems were recorded. Results: 1350 patients were tested, $65.19 \%$ female ( $\mathrm{n}=880)$. Out of 1350 patients, $76.59 \%$ $(\mathrm{n}=1034)$ had been previously diagnosed with any kind of dementia. The most common diagnosis concerning cognitive impairment was $\operatorname{AD}(54.2 \%, \mathrm{n}=560)$ and Vascular Dementia (VaD, 19.7\%, $\mathrm{n}=204)$. Minimental State Examination (MMSE) was performed in all patients and the average score was of $18 \pm 7$. Katz scale for Activities of Daily Living (ADL) was performed in $49.41 \%$ ( $n=667$ ) of patients, Lawton and Brody scale for Instrumental activities of daily living (IADL) in 35.78\% ( $\mathrm{n}=483$ ), and Geriatric Depression Scale (GDS-Yesavage) in 32.89\% $(\mathrm{n}=444)$. The most prominent behavioral symptom was apathy $(12.15 \%, \mathrm{n}=164)$. The most frequent concomitant diseases were: high blood pressure in $52.3 \%$, diabetes in $27.0 \%$ and Dyslipidemia in $23.4 \%$. Conclusions: Through the assessment of clinical surveys throughout Mexico, it was found that the most common form of dementia is AD and it is followed by VaD. Commonly, the Katz, Lawton and Brody, and the GDS-Yesavage scales are clinical assessment tests that are the most commonly used. There are many differences in the use of tests to evaluate patients with dementia across Mexico. For the first time, we were able to identify tendencies in the assessment of dementias by Mexican physicians.
\end{abstract}

Key words: Dementia, Alzheimer's disease, mild cognitive impairment.

Abbreviations: AD: Alzheimer's disease; MMSE: Mini-Mental State Examination; CDT: Clock Drawing Test; ADL: Activities of Daily Living; IADL: Instrumental Activities of Daily Living; CDR: Clinical Dementia Rating.

\section{Introduction}

Dementia is an acquired and progressive syndrome that affects several cognitive capacities such as memory, recognition, behavior and independence; therefore limiting the daily living activities of patients with the disease. Furthermore, dementia has also become a serious public health problem because it strikes directly into the

1. Instituto Biomédico de Investigación, Aguascalientes, México; 2. Hospital Español, Distrito Federal, México; 3. Hospital Ángeles, Puebla, México; 4. Hospital General de Tijuana, Baja California, México; 5. Hospital General de Guanajuato, Guanajuato, México; 6. Universidad Autónoma de Aguascalientes, Aguascalientes, México; 7. Other investigators of the Mexican Group of Specialists in Dementia that are listed in the acknowledgements.

Corresponding Author: Santiago Paulino Ramírez Díaz. MD, PhD, Instituto Biomédico de Investigación, Sierra Fría 218, Bosques del Prado Norte, Aguascalientes, Ags. México 20127, Tel. +52 (449) 9123881 \& 914 6994, Fax +52 (449) 153 3488, E-mail: ramirezdiazsp@gmail.com economy with the needs that these patients generate for an appropriate life quality (1).

Epidemiological studies of dementia in various developing countries have been published (2), however not many studies have been conducted in México. In population above 20 years old, the prevalence of dementia in Mexico is 6.1-7.9\% $(4,34)$ and it was reported the fifth country with the highest prevalence of the disease in Latin America $(2,3)$.

The Mexican Group of Specialist in Dementia is a group of physicians and health professionals (geriatricians, psychiatrists, neurologists) that are dedicated to the diagnosis, treatment, research and spreading awareness of AD and other dementias common in Mexico. These specialists join the group by invitation of other members, regarding their experience in the management of dementia. 
One problem that has arisen in several comparative studies that include in their methodology a follow up of the dementia development, is the diversity and number of instruments used to assess it $(5,6)$. This shows the lack of consensus to assess the evolution of the cognitive impairment, and it gives the physician the freedom to use whichever scale they want, making the comparison in the response to the treatment between patients impossible.

The neuropsychological assessment is one of the most important tests in the process of differential diagnosis of $\mathrm{AD}(7,8)$. This assessment can be done structured and standardized, using questionnaires or tests, or in a personalized way by selecting tests based on the specific deficit found in each patient. Currently there are many scales for assessing the performance of different types of dementia in every aspect that affects the patient, evaluating the cognition, function, behavior, quality of life, depression, caregiver burden and overall dementia severity $(9,10)$. These scales are used to reduce false positive diagnosis when screening specifically for cognitive impairment, making the diagnosis for dementia, its follow up, and the response to treatment quantifiable. Therefore, these instruments should be reliable, practical, and objective to let the physician perform a complete and fast examination in the subsequent visits (11).

The most known test worldwide used to measure cognition is the Mini-Mental State Examination (MMSE) with sensitivity of $79 \%$ and specificity of $95 \%$ (12). The Clock Drawing Test (CDT) with sensitivity of $86 \%$ and specificity of $96 \%$, is another good instrument to measure cognitive dysfunction if it is well employed (13-15). The Katz scale for Activities of Daily Living (ADL) (16), the Lawton and Brody scale for Instrumental Activities of Daily Living (IADL) (17) and the Clinical Dementia Rating (CDR) $(18,19)$ are tools that are often used to evaluate patients with cognitive impairment in Mexico.

There is no doubt that the applications of these tests are vital to properly manage any type of dementia. Unfortunately, despite their reliability, only a few physicians and specialists use them. Based on a standardized questionnaire administered at specialized centers for dementias, this study aims to analyze the clinical background, diagnosis, behavioral problem and the use of different neuropsychological tests for clinical assessment of the patients with dementia in Mexico.

\section{Methods}

This is a descriptive, prospective, cross-sectional multicenter study. Forty-two researchers worked in 34 different memory-specialized centers around Mexico (Figure 1). From February 1st to December 1st, 2012, each center recruited randomly a minimum of 5 new subsequent patients with subjective cognitive impairment.

All patients that visited a memory center or memory specialist (hospital or ambulatory) and had cognitive impairment or moderate to severe memory loss were included in this study. Patients with subjective memory complaints associated with non-central nervous system disease or intracranial occupant causes, or whose diagnosis after consultation was different from dementia were excluded. In addition, those who were not able to complete a MMSE or patients with a life expectancy of less than 6 months were also excluded.

Figure 1

Distribution of centers across Mexico that participated in the study

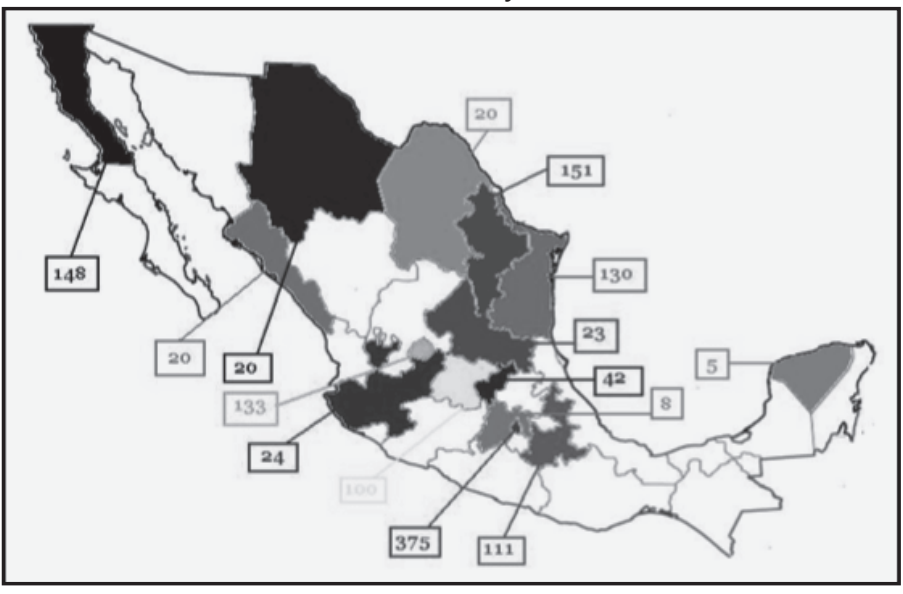

Each patient's visit was carried out according to a standardized clinical practice of each investigator, in which the investigator made an interview, physical exam, reviewed the laboratory and imaging tools and administered a questionnaire. This standardized questionnaire was used to acquire the patient's clinical background and the patient's demographics: gender, age, educational level, socioeconomic status, occupation, comorbidity, type of dementia, duration of symptoms, MMSE score, rating scales, diagnostic imaging and laboratory tools used (i.e. complete blood count or serum Vitamin B12 levels), and psychiatric symptoms. Out of these variables, the qualitative ones were analyzed by their frequency of appearance in each patient. The SPSS software version 20.0 was used to obtain and quantify our data.

\section{Results}

Thirty-four centers throughout Mexico were used and 42 researchers (24 geriatricians, 12 neurologists and 6 psychiatrists) actively participated in the study (Table 1). On average, 39.7 patients were studied per center. The minimum number of patients seen at some centers was five, while some centers included a maximum of 113 patients. A total of 1350 patients participated in this study and $65.19 \%$ were female $(\mathrm{n}=880)$ and $34.81 \%$ were male $(\mathrm{n}=470)$. The mean age was $78.3 \pm 10.7$ years (Table 2$)$. 
Table 1

List of members from the mexican group of specialists in Dementias and number of patients studied in each centre

\begin{tabular}{|c|c|c|c|c|c|}
\hline Centre & Researcher & $\mathbf{N}$ & Centre & Researcher & $\mathbf{N}$ \\
\hline Distrito Federal & $\begin{array}{l}\text { Albert G., Ordoñez L., } \\
\text { Mena F., Montiel A., Pérez } \\
\text { A. }\end{array}$ & 104 & $\begin{array}{l}\text { Distrito Federal } \\
\text { Sinaloa }\end{array}$ & $\begin{array}{l}\text { Pedrero Nieto L. } \\
\text { Pedraza Ibarra S. }\end{array}$ & $\begin{array}{l}20 \\
20\end{array}$ \\
\hline Puebla & Albrecht Junghanns R. & 111 & Distrito Federal & Sosa A., Peña E., Orozco E. & 21 \\
\hline Chihuahua & Bazaldua H., González D. & 20 & Aguascalientes & Ramírez S., Reyes S. & 113 \\
\hline Distrito Federal & Becerra Laparra I. & 20 & Distrito Federal & Rangel López L. & 20 \\
\hline Guanajuato & Bédia Reyes M. & 100 & Tamaulipas & Robles Almaguer E. & 80 \\
\hline Distrito Federal & Carrillo Mora P. & 25 & Distrito Federal & Trujillo De Los Santos Z. & 20 \\
\hline Querétaro & Carvajal García R. & 42 & Coahuila & Valdes Dávila M. & 20 \\
\hline Distrito Federal & Corona Gutiérrez D. & 23 & Jalisco & Ville Corona J. & 20 \\
\hline Jalisco & Cruz Alcalá L. & 24 & Yucatán & Viveros Erosa M. & 5 \\
\hline Nuevo León & Flores Ramírez F. & 31 & Baja California & Zuñiga Gil C. & 102 \\
\hline Tamaulipas & Gonzalez Ortega A. & 50 & Nuevo León & Gonzalez Alanis I. & 20 \\
\hline San Luis Potosí & Rodríguez Leyva I. & 23 & Distrito Federal & Rosas Carrasco O. & 26 \\
\hline San Luis Potosí & Gutierrez R., Iracema L. & 35 & Aguascalientes & Rendon J. & 20 \\
\hline Distrito Federal & Gutierrez Reza M. & 17 & Baja California & Navarrete Báez H. & 20 \\
\hline Distrito Federal & Longoria Ibarrola E. & 62 & Distrito Federal & Becerra Pino M. & 17 \\
\hline Nuevo León & Macías Osuna A. & 65 & Estado De México & Rivera Zetina D. & 8 \\
\hline Baja California & Ng Solís B. & 26 & Total & 1350 & \\
\hline
\end{tabular}

The patients that participated in the study had variety of diseases and the most prevalent were: high blood pressure $(52.37 \%, \mathrm{n}=707)$, diabetes $(26.96 \%, \mathrm{n}=364)$ and dyslipidemia (23.41\%, n=316) (Figure 2).

The MMSE was performed on all patients, the score was corrected for age and years of education and the average score was $18 \pm 7.23 .41 \%(n=316)$ of the patients studied had mild cognitive impairment and the remaining 1034 patients $(76.59 \%)$ were diagnosed with some type of dementia. The most commonly diagnosed dementia among the patients was Alzheimer's disease $(54.2 \%, \mathrm{n}=560)$, followed by various forms of dementia: vascular dementia $(19.7 \%, \mathrm{n}=204)$, mixed dementia $(6.2 \%$, $\mathrm{n}=64)$, frontotemporal dementia $(5.9 \%, \mathrm{n}=61)$, Lewy body dementia $(4.2 \%, \mathrm{n}=43)$ and other types of dementia $(9.7 \%$, $\mathrm{n}=102$ ).

The duration of symptoms varied: $7.52 \%(n=142)$ had cognitive symptoms lasting from 0 to 6 months before the visit, $13.85 \%(\mathrm{n}=187)$ for 6 to 12 months, $24.59 \%(\mathrm{n}=332)$ for 1 to 2 years, $29.70 \%(\mathrm{n}=401)$ for $2-5$ years, and $21.33 \%$ $(\mathrm{n}=288)$ over 5 years with the symptoms.

Eighty-eight percent of the patients $(n=1188)$ had a diagnostic imaging test, either Brain Computed Tomography (CT) or Brain Magnetic Resonance Imaging (MRI).

Each investigator had the option to use whichever assessment scale they preferred. A variety of assessment tools were used, the most common was the Katz Scale for ADL (16) $(49.41 \%, \mathrm{n}=667)$, followed by Lawton and
Brody Scale for IADL (17) (35.78\%, $\mathrm{n}=483)$, the Geriatric Depression Scale (GDS-Yesavage) (20) (32.89\%, $\mathrm{n}=444)$, the Clinical Dementia Rating (CDR) (18) $(15.93 \%, n=215)$, the Clock Drawing Test (CDT) (14) $(14.22 \%, \mathrm{n}=192)$, the Zarit Burden Interview (ZBI) (scale performed in the caregiver) (21) $(14.15 \%, \mathrm{n}=191)$, the Global Deterioration Scale (GDS-Reisberg) (22) (12.74\%, $\mathrm{n}=172)$ and lastly, the Neuropsychiatric Inventory(NPI) (23) $(8.22 \%, n=111)$. Other scales less commonly used were: the Hachinski Ischemic Scale (HIS) (24) $(6.44 \%, \mathrm{n}=87)$, the Informant Questionnaire on Cognitive Decline in the Elderly (IQCODE) (25) $(6.14 \%, \mathrm{n}=83)$, the Alzheimer's Disease Assessment Scale Cognitive Subscale (ADAS-Cog) (26) $(4.44 \%, \mathrm{n}=60)$ and the Cornell scale for depression in dementia (27) $(4.37 \%, \mathrm{n}=59)$. The assessment scales used for the evaluation of the patients are summarized in Table 3.

With an interview and without using any clinical scale; almost three quarters of the patients $(72.07 \%, \mathrm{n}=973)$ did not show any psychiatric symptoms at the time of consultation. However, as noted by the interviewers using the NPI scale, the most common symptom noted was apathy in $16.9 \%(n=164)$ of patients, followed by anxiety in $15.3 \%(n=149)$ and lastly, hallucinations in $14.2 \%(n=138)$ (Figure 3). 
Table 2

Demographic characteristics of the population

\begin{tabular}{lcc}
\hline & $\mathbf{n}$ & $\%$ \\
\hline Sex & 470 & 34.81 \\
Male & 880 & 65.19 \\
Female & & \\
Schooling & 1125 & 83.64 \\
Basic & 81 & 6.02 \\
Medium & 139 & 10.33 \\
Superior & & \\
Employment & 1025 & 75.93 \\
Retired & 325 & 24.07 \\
Not retired & & \\
Socioeconomic status & 282 & 20.89 \\
High & 777 & 57.56 \\
Medium & 291 & 21.56 \\
Low &
\end{tabular}

Table 3

Distribution of the main neuropsychological assessment tools used in specialized centers across Mexico

\begin{tabular}{lccc}
\hline Assessment tools & N & $\%$ & $\begin{array}{c}\text { Average } \\
\text { score }\end{array}$ \\
\hline Katz (ADL) & 667 & 49,41 & 4 \\
Lawton \& broody (ADL/IADL) & 483 & 35,78 & 5 \\
Geriatric Depression Scale (GDS) & 444 & 32,89 & 7 \\
Clinical Dementia rating (CDR) & 215 & 15,93 & 1,5 \\
Clock drawing test (cdt) & 192 & 14,22 & 55 \\
Zaritburden interview (ZBI) & 191 & 14,15 & 55 \\
Global deterioration Scale (gds) & 172 & 12,74 & 5 \\
Neuropsychiatric Inventory (NPI) & 111 & 8,22 & - \\
Hachinski Ischaemic Scale (HIS) & 87 & 6,44 & 6 \\
IQCODE test & 83 & 6,14 & 5 \\
Alzheimer's disease assesment (Adas- & 60 & 4.44 & - \\
cog) & & & \\
Cornell scale for depression in demen- & 59 & 4.37 & - \\
tia & & & \\
\hline
\end{tabular}

\section{Discussion}

The National Dementia Survey outlines a general approach of the diagnosis and management of dementias in Mexico, the sample size is significant and capable to define most of the habits and practices among specialists of dementia in this country for screening, follow-up and treatment. Distrito Federal and central area of the country gather the centers with most patients analyzed because most of the Mexican population lives in that area (34).
It is well established that dementia rates are growing in high speed. Worldwide there are some descriptions of epidemiological surveys of this disease; most of them describe its prevalence, risk factors and neurological conditions $(32,33)$.

\section{Figure 2}

Distribution of patient's background diseases: HBP, High blood pressure; DM, Diabetes; DL, Dyslipidemia; COPD, Chronic obstructive Pulmonary Disease; MI, Myocardial Infarction; TBI, Traumatic Brain Injury; RF, Renal Failure;

OAD, Osteoarthritic diseases; HT, Hypothyroidism

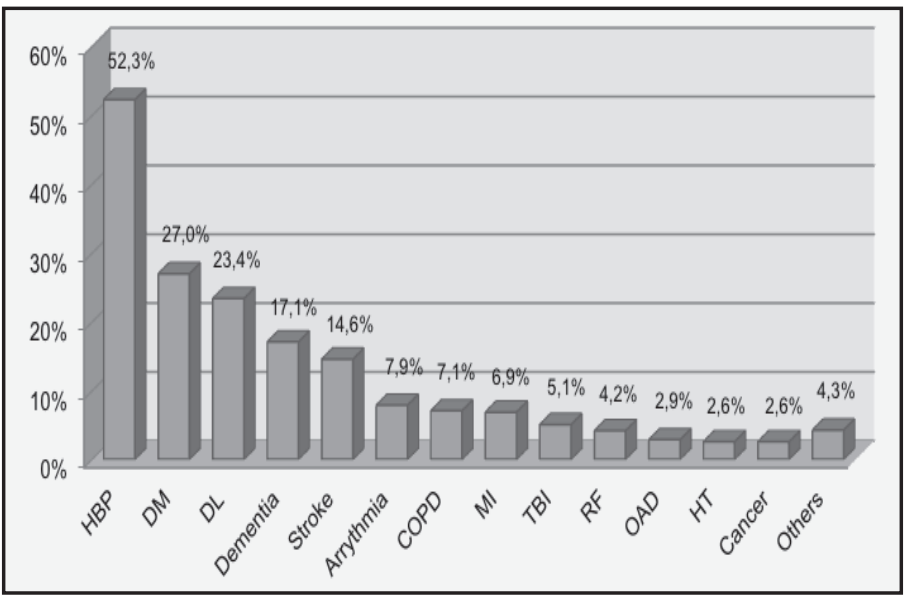

The most common comorbidities and background diseases in our study were cardiovascular, similar to that reported in the national literature (28).This study shows a well-supported diagnosis of cognitive disorders linked to dementia thanks to the laboratory and imaging tests performed by most centers to support the diagnosis. This tests are necessary to exclude a space-occupying lesion or any other condition outside neurodegenerative patterns, they improve accuracy on differential diagnosis and can be considered for monitoring the disease process or disease progression in its follow up (7). In addition, Alzheimer's disease and vascular dementia were the most common diseases, as reported in previous studies $(2,4)$.

Many articles show that despite the broad and extensive development of evaluation tools, particularly in Alzheimer's disease and other dementias, their appropriate use in monitoring and screening for clinical practice is not used properly (29). In common clinical practice we cannot perform all of the tests described previously because their use and application is not interchangeable. Some tests were designed for particular conditions associated with the cognitive impairment or to evaluate just a part of it. The assessment of the activities of daily living were the most used scales in patients with dementia. It is noteworthy that the third most commonly used scale was depression screening in patients with dementia, which supports the relationship between these conditions (30). 
The characteristics of the scales used for dementia assessment may limit their application; conditions as language, time to perform the test, training of the rater; and other different circumstances concerning the patient, like psychiatric condition, can make the physician or specialist unable to implement correctly a neuropsychological assessment (31). In the sample, most of the patients did not complain of behavioral and psychological symptoms at the time of consultation contrary to what is stated in the literature, where over a half of the patients do present with these symptoms (35).

Even though we had a very good response from all over the country with over 1300 patients in the database (Figure 1) we did not cover all the country. We are now working in getting more centers involved for a better sample of the country.

\section{Figure 3}

Distribution of prominent associated psychiatric problems

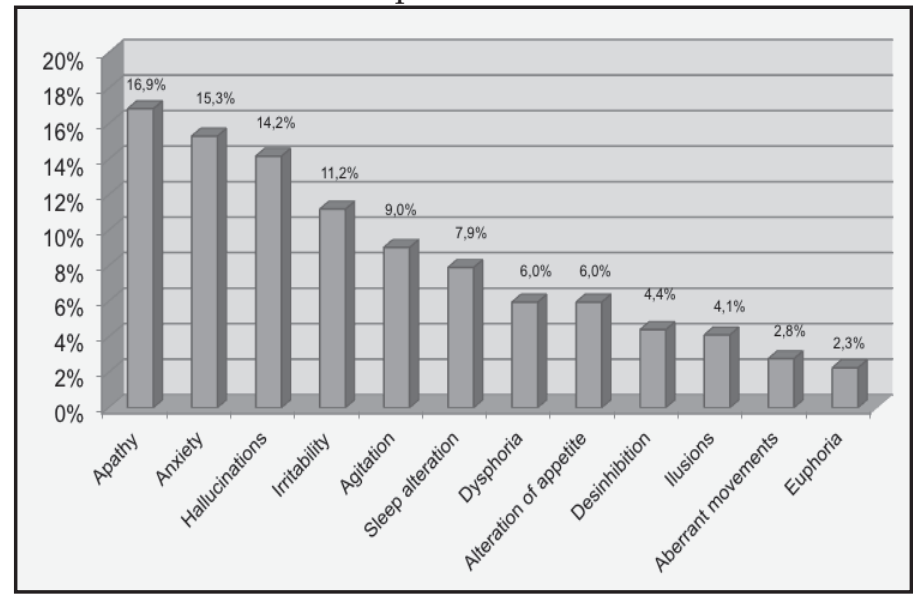

\section{Conclusions}

Only a few clinical assessments scales are used for the evaluation of dementia. The Katz for ADL, LawtonBrody for IADL and the GDS-Yesavage scales are the most common tests used for the assessment of dementia in México. There are many differences in the tests used in the centers to evaluate patients with dementia across Mexico. Unifying the way we use diagnostic criteria and the use of neuropsychological assessment tools to evaluate cognitive impairment is required. Nevertheless, it is important to mention that this work is the first attempt to get the whole country represented. The National Group of specialists in dementia are a group of physicians (geriatricians, neurologists and psychiatrists) working together to unify criteria for diagnose, treatment and follow-up patients with dementia.

Acknowledgments: Investigators that participated in the survey: Acero J (Aguascalientes),Albert G (Distrito Federal), Albrecht R (Puebla), Almanza E (Aguascalientes), Barba V (Aguascalientes), Bazaldua H (Chihuahua), Becerra I (Distrito Federal), Becerra M (Distrito Federal), Caldera J (Aguascalientes), Carrillo P (Distrito Federal), Carvajal R (Querétaro), Corona D (Distrito Federal), Cruz L (Jalisco), Flores F (Nuevo León), Gómez C (Aguascalientes), González A (Tamaulipas), González D (Chihuahua), González I (Nuevo León), Gutiérrez
M (Distrito Federal), Gutiérrez R (San Luis Potosí), Iracema L (San Luis Potosí), Longoria E (Distrito Federal), Macías A (Nuevo León), Mena F (Distrito Federal), Montiel A (Distrito Federal), Navarrete H (Baja California), Ordoñez L (Distrito Federal), Orozco E (Distrito Federal), Pedraza S (Sinaloa), Pedrero L (Distrito Federal), Peña E (Distrito Federal), Pérez A (Distrito Federal), Ramírez S (Aguascalientes), Rangel L (Distrito Federal), Rendón J (Aguascalientes), Reyes S (Aguascalientes), Rivera D (Estado de México), Robles E (Tamaulipas), Rodríguez I (San Luis Potosí), Rosas O (Distrito Federal), Solís B (Baja California), Sosa A (Distrito Federal), Trujillo Z (Distrito Federal), Valdez M (Coahuila), Ville-Corona J (Jalisco), Viveros M (Yucatán), Zúñiga C (Baja California).

Conflict of interest: All authors declare that they have no conflicts of interest. No competing financial interests exist.

\section{References}

1. Holsinger T, Deveau J, Boustani M, Williams JW. Does this patient have dementia? JAMA 2007;297: 2391-2404.

2. Llibre Rodríguez JJ, Ferri CP, Acosta D, Guerra M, Huang Y, Jacob KS Krishnamoorthy ES, Salas A, Sosa AL, Acosta I, Dewey ME, Gaona C, Jotheeswaran AT., LiS, Rodríguez D, Rodríguez G, Kumar PS, Valhuerdi A y Prince M. Prevalence of dementia in Latin America, India, and China: a population-based cross-sectional survey. Lancet, 2008;372: 464-474.

3. Prince M, Acosta D, Albanese E, Arizaga R, Ferri CP, Guerra M, Huang Y, Jacob KS, Jiménez-Velázquez IZ, Rodríguez JL, Salas A, Sosa AL, Sousa R, Uwakwe R, van der PR, Williams J, Wortmann M. Ageing and dementia inlow and middle income countries-using research to engage with public and policy makers. Int Rev Psychiatry. 2008;20 (4):332-43.

4. Mejía-Arango S \& Gutiérrez LM. Prevalence and Incidence Rates of Dementia and Cognitive Impairment No Dementia in the Mexican Population: Data from the Mexican Health and Aging Study. J Aging Health. 2011;23: 10501074 .

5. Robert P, Ferris S, Gauthier S, Ihl R, Windblad B, Tennigkeit F. Review of Alzheimer's disease scales: is there a need for a new multi-domain scale for therapy evaluation in medical practice? Alzheimers Res Ther 2010;26;2(4):24.

6. Ramirez Diaz S, Gregorio P, Ribera Casado J, Reynish E, Ousset PJ, Vellas, B. The need for a consensus in the use of assessment tools for Alzheimer's disease: the Feasibility study(assessment tools for dementia in Alzheimer Centers across Europe), a European Alzheimer's Disease Consortium's (EADC) survey. Int J Geriatr Psychiatry 2005;20: 744-748.

7. Gutierrez-Robledo L, Zúñiga-Gil C, Resnikoff-Fischer. Diagnostico de las demencias. Arch Neurocien 2006;1: 14-26.

8. Renaud D, Mulin E, Mallea P, Robert P. Measurement of Neuropsychiatric Symptoms in Clinical Trials Targeting Alzheimer's Disease and Related Disorders. Pharmaceuticals 2010;3: 2387-2397.

9. Brodaty H, Low LF, Gibson L, Burns K. What Is the Best Dementia Screening Instrument for General Practitioners to Use? Am J Geriatr Psychiatry 2006;14:391-401.

10. Zahinoor I, Tarek R, Shulman K. Brief cognitive screening instruments: an update. Int J Geriatr Psychiatry 2010;25: 111-120.

11. Sheehan B. Assessment scales in dementia. Ther Adv Neurol Disord 2012;5(6): 349-358.

12. Folstein M, Folstein S, McHugh P. Mini Mental State: a practical method for grading the cognitive state of patients for the clinician. J Psychiatr Res 1975;12:189-98.

13. Brodaty $\mathrm{H}$ \& Moore C. The Clock Drawing Test for dementia of the Alzheimer's type: a comparison of three scoring methods in a memory disorders clinic. Int J Geriatr Psychiatry 1997;12: 619-627.

14. Shulman K, Shedletsky R, Silver I. The challenge of time. Clock drawing and cognition function in the elderly. Int J Geriatr Psychiatry 1996;1: 135-40.

15. Shulman K. Clock-drawing: is it the ideal cognitive screening test? Int J Geriatr Psychiatry 2000;15: 548-561.

16. Katz S, Ford A, Moskowitz R, Jackson B, Jaffe M. Studies of illness in the aged. The index of ADL: a standardized measure of biological and psychological function. JAMA 1963;185: 914-919.

17. Lawton M, Brody E. Assessment of older people: self-maintaining and instrumental activities of daily living. Gerontologist 1969;179-186.

18. Hughes CP, Berg L, Danziger WL, Coben LA, Martin RL. A new clinical scale for the staging of dementia. Br J Psychiatry 1982;140: 566-572.

19. Morris JC. The Clinical Dementia Rating (CDR): current version and scoring rules. Neurology 1993;43: 2412-2414.

20. Yesavage JA, Brink TL, Rose TL, Lum O., Huang V., Adey M., Leirer V. Development and validation of a geriatric depression screening scale: A preliminary report. J Psychiatr Res 1983;17, 37-49.

21. Zarit S, Reever K, Bach-Peterson J.1980. Relatives of the impaired elderly: correlates of feeling of burden. Gerontologist 1980;20: 649-655.

22. Reisberg B, Ferris S, De Leon M, Crook T. The global deterioration scale for assessment of primary degenerative dementia. Am J Psychiatry 1982;139:1136-9.

23. Cummings J, Mega M, Gray K, Rosenberg-Thompson S, Carusi D, 
Gornbein J. The Neuropsychiatric Inventory: comprehensive assessment of psychopathology in dementia. Neurology 1994;44:2308-2314.

24. Hachinski V, Oveisgharan S, Romney A, Shankle W. Optimizing the Hachinski Ischemic Scale. Arch Neurol. 2012;69:169-75.

25. Jorm A, Jacomb A. The Informant Questionnaire on Cognitive Decline in the Elderly (IQCODE): Socio-demographic correlates, reliability, validity and some norms. Psycol Med 1989;19: 1015-1022.

26. Rosen WG, Mohs RC, Davis KL. A new rating scale for Alzheimer's disease. Am J Psychiatry 1984;141: 1356-1364.

27. Alexopoulous GS, Abrams RC, Young RC, Shamoian CA. Cornell scale for depression in dementia. Biol Psychiatry 1988;2 3:271-284.

28. Mejía-Arango S, Miguel-Jaimes A, Villa A, Ruiz-Arregui L, GutiérrezRobledo L. Deterioro cognoscitivo y factores asociados en adultos mayores en México. Sal Púb Méx 2007;49: 475-481.

29. Shulman KI, Herrmann N, Brodaty H, et al. IPA survey of brief cognitive screening instruments. Int Psychogeriatr 2006;18: 281-294.

30. Milne A, Culverwell A, Guss R, Tuppen J, Whelton R. Screening for dementia in primary care: a review of the use, efficacy and quality of measures. Int Psychogeriatr 2008;20: 911-926.
31. Iracleous P, Nie JX, Tracy CS. Primary care physicians' attitudes toward cognitive screening: findings from a national postal survey. Int J Geriatr Psychiatry 2009;25: 23-29.

32. Prince M, Bryce R, Albanese E, Wimo A, Ribeiro W, Ferri CP. The global prevalence of dementia: a systematic review and metaanalysis. Alzheimers Dement. 2013;9(1):63-75.

33. Rizzi L. Rosset I, Roriz-Cruz M. Global Epidemiology of Dementia: Alzheimer's and Vascular Types. BioMed Res Int vol. 2014, ID 908915, doi:10.1155/2014/908915.

34. Gutiérrez JP, Rivera-Dommarco J, Shamah-Levy T, Villalpando-Hernández S, Franco A, Cuevas-Nasu L, Romero-Martínez M, Hernández-Ávila M. 2012. Encuesta Nacional de Salud y Nutrición 2012. Resultados Nacionales. Cuernavaca, México: Instituto Nacional de Salud Pública (MX).

35. Mirakhur, A, Craig D, Hart, DJ, McIlroy, SP and Passmore, AP. Behavioural and psychological syndromes in Alzheimer's disease. Int J Geriatr Psychiatry 2004;19, 1035- 1039.

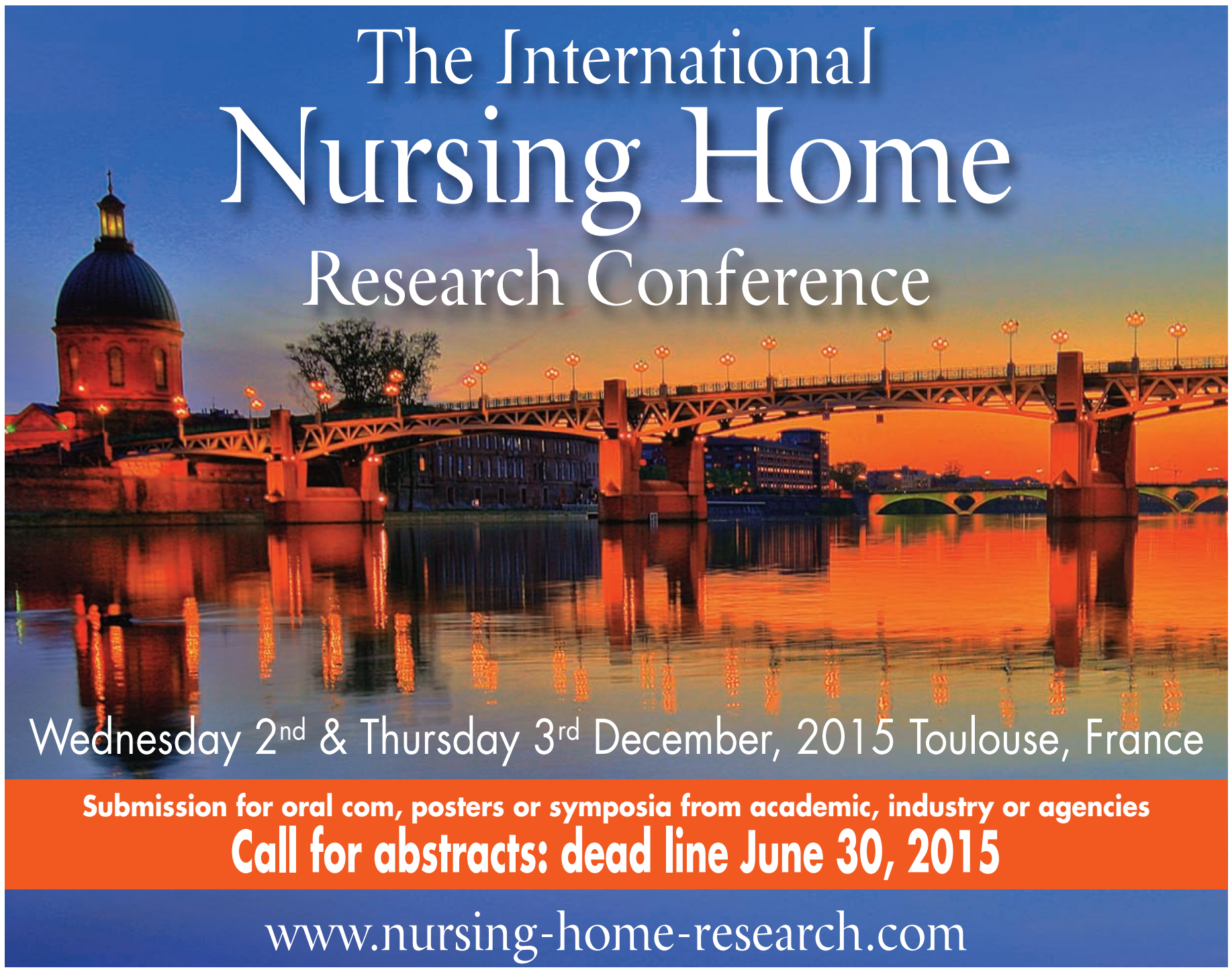

